\title{
XL. Regnault's determination of the specific heat of steam
}

\section{J. Macfarlane Gray}

To cite this article: J. Macfarlane Gray (1882) XL. Regnault's determination of the specific heat of steam , Philosophical Magazine Series 5, 13:82, 337-340, DOI: $10.1080 / 14786448208628400$

To link to this article: http://dx.doi.org/10.1080/14786448208628400

巴nublished online: 28 Apr 2009.

Submit your article to this journal $\pi$

ЏII Article views: 3

Q View related articles $\square$

Citing articles: 1 View citing articles 5 
trical experiments) that there is a temperature-level in nature for the incandescence of gases, much lower than that of the lowtemperature oxygen-spectrum of these pages. Wherefore, if we could artificially produce that kind of ultra-low-temperature illumination, electric probably, we might find that the $\alpha$ (alpha) band in the solar sunset spectrum represented the oxygen, while the $A$ and $B$ bands showed us the nitrogen gas thereofthey two being the mighty gas constituents known so well to every one (except telluric-line solar spectroscopists) to exist in the earth's atmosphere, and in such overpowering quantity as to practically exclude every thing else except watery vapour.

XL. Regnault's Determination of the Specific Heat of Steam. By J. Macfarlane GraY*.

REGNAULT'S experiments on the specific heat of vapours I have been interpreted by Regnault as giving results not at all in accordance with the deduction from the kinetic theory of gases, that, for matter travelling in single molecules, the product of the molecular weight by the specific heat is a constant for all substances. I have been led, by considering the order of temperature-pressures for steam, to conclude that the above deduction is true for steam; and I have no doubt, also for all matter travelling in single molecules. When, in 1880, I laid my conclusions before the Physical Society as being corroborated by Regnault's dynamical experiments, it was objected that Regnault's direct thermal experiments gave results widely different from my conclusions; and the report on my paper was that that difference proved that, in the corroborations I had pointed out, I had been led away by merely numerical coincidence.

I will now show that Regnault's thermal experiments have been misinterpreted by Regnault himself, and that he ought to have read the specific heat of steam, according to his experiments, to be exactly in accordance with the deduction of the kinetic theory.

The method of the experiments was to generate steam at $100^{\circ} \mathrm{C}$, to superheat it under atmospheric pressure to (say) $125^{\circ}$ in one set of experiments, condensing it in a calorimeter to ascertain what quantity of heat was given up, down to $0^{\circ}$. In a second set of experiments with the same apparatus, the temperature was raised to (say) $225^{\circ}$, while the steam was still at atmospheric pressure; this was also condensed in the

* Communicated by the Physical Society, having been read at the Meeting on February 25, 1882. 
same calorimeter. It was found that the heat given up by the steam at $225^{\circ}$ exceeded that given up by the steam at $125^{\circ}$ by 48.051 units of heat; and, dividing by the difference of temperature (100), Regnault found $0 \cdot 48051$ for the specific heat of steam at constant pressure.

In these experiments the superheating to $125^{\circ}$ was, no doubt, intended to thoroughly dry the steam, so as to get, in the quantity of heat abandoned in the first set of experiments, the entire heat of complete gasefication, because, if still some moisture remained in the steam, the latent heat of evaporation of that moisture would be included in the difference-quantity supposed to be due to the specific heat of temperature-raising, and, by that amount, the result would be too high.

It appears to me that the completion of the evaporation of suspended moisture cannot be accomplished between $100^{\circ}$ and $125^{\circ}$; but it will be more likely to be carried on between $125^{\circ}$ and $225^{\circ}$. Particles of liquid remain at the pressure-temperature whatever be the superheated temperature of the gas in which they are suspended. The rate of evaporation of those particles will therefore depend upon the temperature-difference; and in the lower range of temperatures but little of the moisture will be evaporated in its rapid passage through a worm heated to only $25^{\circ}$ in excess of the pressure-temperature. In the second set of experiments the excess of temperature was $125^{\circ}$.

To test this, let similar experiments be made at $100^{\circ}$; and if the resulting apparent specific heats between $100^{\circ}$ and $125^{\circ}$ are higher than those obtained by Regnault between between $125^{\circ}$ and $225^{\circ}$, then my argument is demolished; but if the results are smaller, then my suspicions have been justified, and a correction is required on the results as given by Regnault. Fortunately for my object, Regnault has left us (in vol. i., at page 695) the data of thirty-eight reliable experiments on the "total heat" of steam at $100^{\circ}$ down to $0^{\circ}$, giving the mean $=636.70$ units of heat. I have, with this "total heat" for $100^{\circ}$, compared the results of the experiments on the steam of $125^{\circ}$-in precisely the same way as Regnault worked for the interval between $125^{\circ}$ and $225^{\circ}$ (these experiments are recorded in vol. ii., pages 167-178). The results of my calculations are given below. The first two series were merely preparatory trials to arrive at the best form of apparatus; and only a few grammes of vapour were passed through the worm at each of those experiments. In the third and the fourth series ten times as much vapour was passed through on each occasion. Regnault says:- “J'ai pu opérer ainsi sur des quantités de vapeur beaucoup plus considérables, et diminuer l'importance 
relative des corrections produites par les causes perturbatrices." This consideration is still more important when the range of temperature is limited to $25^{\circ}$-only one fourth of the range from which Regnault deduced his result. The large calorimeter was used only in the third and fourth series.

\begin{tabular}{|c|c|c|c|}
\hline First series. & Second series. & Third series. & Fourth series. \\
\hline$\cdot 280$ & $\cdot 546$ & $\cdot 299$ & $\cdot 386$ \\
\hline$\cdot 465$ & •591 & •314 & 381 \\
\hline$\cdot 417$ & $\cdot 567$ & $\cdot 340$ & .346 \\
\hline$\cdot 377$ & & .375 & .309 \\
\hline$• 463$ & Mean 567 & $\cdot 400$ & $\cdot 427$ \\
\hline Mean ·400 & & $\cdot 411$ & $\cdot 463$ \\
\hline Mean -400 & & .049 & Mean $\cdot 3853$ \\
\hline Preparat & y trials. & $\cdot 405$ & \\
\hline & & $\cdot 415$ & \\
\hline & & Mean $\cdot 3721$ & \\
\hline
\end{tabular}

That the method of calculation may be perfectly clear, I give the particulars for the first experiment in the fourth series. Superheating to $124^{\circ} \cdot 81$, each unit of vapour gave up $646 \cdot 28$ units of heat down to $0^{\circ}$. Steam at $100^{\circ}$ gave up 636.70 down to $0^{\circ}$.

$$
\frac{646 \cdot 28-636 \cdot 70}{124 \cdot 81-100}=\cdot 386 \text {. }
$$

The quantity of vapour in this experiment was 102.62 grms. ; the quantity in the first of the first series was only $8.957 \mathrm{grms}$.

The fourth series was made with an apparatus which was an improvement on that used in the third series; and, taking that series only, adding the probable amount of moisture which would remain at $100^{\circ}$ temperature (say 1 per cent. on the $\cdot 385$ ), the result is $\cdot 389$; this, on other grounds, I believe to be nearly correct. If, however, neglecting the other grounds for my opinion, we take the mean of the means of the third and the fourth series, we get

$$
\frac{\cdot 3721+\cdot 3853}{2}=\cdot 3787 \text {. }
$$

This is what Regnault might fairly have done.

If we now calculate what Regnault's experiments would give as the kinetic-theory result,- - we get the specific heat of hydrogen, at page 121 , " mean $=3 \cdot 4090$;" and taking the molecular weight of steam $=17 \cdot 96$, we find the specific heat 
of steam

$$
3 \cdot 409 \times \frac{2}{17 \cdot 96}=\cdot 3796 .
$$

That is to say, the kinetic theory and the thermal determination give almost identically the same number.

This is, I believe, the first experimental proof that the law of "inversely as the molecular weights" applies to compound gases.

XLI. Acoustical Observations.-IV. By LORD RAYLEIGH, F.R.S., Professor of Experimental Physics in the University of Cambridge*.

On the Pitch of Organ-pipes.-Slow versus quick Beats for comparison of Frequencies of Vibration. - Estimation of the Direction of Sounds with one ear.-A Telephone-experiment.-Very high Notes.-Rapid Fatigue of the Ear.-Sensitive Flames.

\section{On the Pitch of Organ-pipes.}

TN the Philosophical Magazine for June 1877 I described 1 some observations which proved that the note of an open organ-pipe, when blown in the normal manner, was higher in pitch than the natural note of the pipe considered as a resonator. The note of maximum resonance was determined by putting the ear into communication with the interior of the pipe, and estimating the intensity of sounds of varying pitch produced externally.

A more accurate result may be obtained with the method used by Blaikley $\dagger$, in which the external sound remains constant and the adjustment is effected by tuning the resonator to it. About two inches were cut off the upper end of a twofoot metal organ-pipe, and replaced by an adjustable paper slider. At a moderate distance from the lower end of the pipe a tuning-fork was mounted, and was maintained in regular vibration by the attraction of an electromagnet situated on the further side, into which intermittent currents from an interrupter were passed. Neither the fork nor the magnet were near enough to the end of the pipe to produce any sensible obstruction. By comparison with a standard, the pitch of the fork thus vibrating was found to be 255 of König's scale. The resonance of the pipe was observed from a position not far from the upper end, where but little of the sound of the fork could be heard independently; and the

* Communicated by the Author.

$\dagger$ Phil. Mag. May 1879. 